\title{
An improved demonstration of charge conservation
}

\section{Citation}

Rueckner, Wolfgang. 2007. An improved demonstration of charge conservation. American Journal of Physics 75 (9): 861-863.

\section{Published Version}

10.1119/1.2721589

\section{Permanent link}

http://nrs.harvard.edu/urn-3:HUL.InstRepos:27413765

\section{Terms of Use}

This article was downloaded from Harvard University's DASH repository, and is made available under the terms and conditions applicable to Other Posted Material, as set forth at http:// nrs.harvard.edu/urn-3:HUL.InstRepos:dash.current.terms-of-use\#LAA

\section{Share Your Story}

The Harvard community has made this article openly available.

Please share how this access benefits you. Submit a story.

Accessibility 


\title{
APPARATUS AND DEMONSTRATION NOTES
}

Frank L. H. Wolfs, Editor

Department of Physics and Astronomy, University of Rochester, Rochester, New York 14627

\begin{abstract}
This department welcomes brief communications reporting new demonstrations, laboratory equipment, techniques, or materials of interest to teachers of physics. Notes on new applications of older apparatus, measurements supplementing data supplied by manufacturers, information which, while not new, is not generally known, procurement information, and news about apparatus under development may be suitable for publication in this section. Neither the American Journal of Physics nor the Editors assume responsibility for the correctness of the information presented.

Manuscripts should be submitted using the web-based system that can be accessed via the American Journal of Physics home page, http://www.kzoo.edu/ajp/ and will be forwarded to the ADN editor for consideration.
\end{abstract}

\section{An improved demonstration of charge conservation}

\author{
Wolfgang Rueckner \\ Science Center, Harvard University, Cambridge, Massachusetts 02138
}

(Received 23 February 2007; accepted 9 March 2007)

[DOI: $10.1119 / 1.2721589$ ]

\section{INTRODUCTION}

A previous note ${ }^{1}$ described a quantitative demonstration of charge conservation intended for lecture-hall audiences. In that demonstration, a bundle of rabbit's fur is pulled out of a Teflon-lined metal tube and then placed into a plain metal tube. Voltage measurements of the two tubes show them to be of equal magnitude but opposite in sign.

The demonstration has worked flawlessly over the years but, in this author's opinion, has some pedagogical difficulties. Conservation of charge is typically introduced in the first few lectures of the electricity and magnetism course, before the concepts of voltage and capacitance are discussed. However, the voltage, $V$, is the actual quantity measured in this demonstration and one needs to argue that this is also a measurement of charge, $Q$, since $V=Q / C$. This relationship is well known to physics instructors, but not their introductory students. Furthermore, if the voltages are the same, this means the charges are the same provided that the capacitances are the same. Using unfamiliar concepts to explain how the demonstration works leaves something to be desired. Secondly, the demonstration uses rather esoteric materials: rabbit's fur, a Teflon-lined metal tube, and a highimpedance digital electrometer. These are not items familiar to beginning physics students. The experiment described in this note solves these pedagogical problems and improves the demonstration considerably.

\section{THE IMPROVEMENTS}

One can hear the crackles from the sparks generated when taking off a fleece sweater in winter, especially if you are wearing cotton clothing underneath. The sparks are even more dramatic when trying to separate a fleece garment from the rest of the laundry that has just come out of the dryer. Clearly, these common items have great potential for electrostatics experiments. The triboelectric series presented in Table I corroborates this. Fleece is usually $100 \%$ polyester and appears on this list well below cotton and silk; other clothing materials, such as wool, rayon, and nylon, are even higher up the list than silk. The greater the separation on the list, the greater the triboelectric effect. ${ }^{2}$ Although it is hard to beat the combination of Teflon and rabbit's fur, it certainly is not necessary for this demonstration; everyday clothes will do the trick nicely. A fleece combined with either a cotton or silk shirt, or a woolen sweater, works very well.

Tall aluminum cooking pots have replaced the metal tubes of Ref. 1. The pots need to be identical and large enough to easily hold the items of clothing. They are supported by an appropriate insulator above a conducting ground plane. Figure 1 shows the pots sitting on inverted Pyrex baking pans.

The electroscope is typically introduced in electricity and magnetism courses as a fundamental charge-measuring device. Instead of high-impedance digital electrometers, two identical electroscopes are utilized in this demonstration to measure the charge of each pot.

\section{THE DEMONSTRATION}

\section{A. The "standard" presentation}

The two items of clothing, e.g., fleece and wool sweater, are placed in close contact in one of the pots. Next, each pot is fully discharged by a momentary electrical contact to the ground plane. One item of clothing is then removed and placed in the other (empty) pot. The electroscopes measure the charge developed as a result of this transfer; they should register the same magnitude of charge if charge is conserved.

The next step is to ascertain the polarity of the charges of the two pots and show that the two pots are oppositely charged. For this part of the demonstration one needs a charge of known sign for reference, which should have been introduced and used earlier in the lecture. PVC pipe rubbed with a cotton T-shirt works well; the PVC becomes negatively charged. Insert the charged PVC pipe into the pot containing the fleece, without touching the pot or fleece, and the connected electroscope will indicate an increase in charge. This means the pot containing the fleece is negatively 
Table I. Triboelectric series. Experimenters have established lists of the relative affinities materials have for gaining and losing electrons. Materials with similar properties clump together on the list and don't interact strongly. This list has been expanded from one published by Hendicks (Ref. 6). That author notes that the series is reproducible only in rare circumstances; cleanliness, humidity, and manufacturing differences affect the ordering.

\begin{tabular}{|c|c|}
\hline Rabbit's fur & most positive (readily loses electrons) \\
\hline Lucite (acrylic) & \\
\hline Bakelite & \\
\hline Acetate & \\
\hline Glass & \\
\hline Quartz & \\
\hline Mica & \\
\hline Human hair & \\
\hline Nylon & \\
\hline Rayon & \\
\hline Wool & \\
\hline Cat's fur & \\
\hline Silk & \\
\hline Paper & \\
\hline Cotton & \\
\hline Wood & \\
\hline Sealing wax & \\
\hline Amber & \\
\hline Resins & \\
\hline Hard rubber & \\
\hline Metals & \\
\hline Polyester & \\
\hline Polystyrene (Styrofoam) & \\
\hline Orlon & \\
\hline Saran Wrap & \\
\hline Polyurethane & \\
\hline Polyethylene & \\
\hline Polypropylene & \\
\hline Sulfur & \\
\hline Celluloid & \\
\hline Vinyl (PVC) & \\
\hline Teflon & most negative (tends to attract electrons) \\
\hline
\end{tabular}

charged. In the same manner, insert the PVC pipe into the pot containing the wool sweater. That pot's electroscope will indicate a decrease in charge, meaning that it is positive.

An additional step may be taken to reinforce the concept

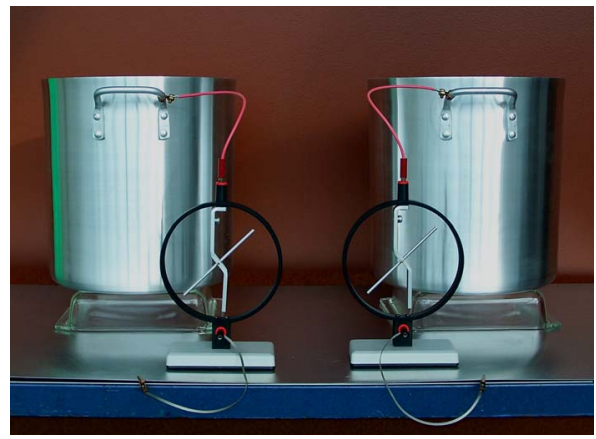

Fig. 1. The demonstration apparatus. The cooking pots are supported over the ground plane by Pyrex baking pans. Note that the shields of the electroscopes are electrically connected to the ground plane. of charge conservation. If one item of clothing is taken out of its pot and reunited with the other, both electroscopes will once more indicate zero net charge.

\section{B. Variations of the demonstration}

The triboelectric effect requires that the materials in contact be dissimilar. Consequently, if the two items of clothing are of the same material, no charge will be observed when they are separated; the electroscopes will indicate zero. If time permits, this is a worthwhile exercise.

The experiment may also be performed with just one piece of clothing, in which case the metal pot acts as the second material in the triboelectric effect. Metals are more-or-less in the middle of the triboelectric series and the effect is not as dramatic; only around $20 \mathrm{nC}$ of charge $(50 \mathrm{~V}$ for $C$ $\approx 400 \mathrm{pF}$ ) will be produced. To that end, more sensitive electroscopes will need to be used.

\section{TECHNICAL DETAILS}

As the saying goes, "the devil is in the details," and successful electrostatic demonstrations are no exception. Starting from the ground up, the following details are very important.

\section{A. Ground plane}

Generally speaking, all electrostatic demonstrations benefit from having a good conducting ground plane. This is especially true when trying to completely discharge something. Stray charges on the person or surrounding objects can easily nullify or even contradict results one wishes to demonstrate. Measurements of charge and electric potentials of objects are affected by their capacitance, and a ground reference is a must. Whether you use a sheet of thin aluminum ${ }^{3}$ or simply spread out aluminum foil on the bench top or cart, it should be properly grounded to a real electrical ground. The metal cover of the nearest AC outlet is usually a convenient ground connection.

\section{B. Electroscopes}

Regardless of which electroscopes you choose to use, make sure they are identical and can handle large quantities of charge. ${ }^{4}$ Test them together, when attached in parallel to a high-voltage power supply, in order to verify that they both give the same deflection over a range of voltages.

\section{Pots and supports}

The two identical cooking pots are aluminum 24-qt stock pots, ${ }^{5}$ which are large enough to easily hold two items of clothing. Also, their depth should be greater than their width so that the items of clothing lie in the bottom third (or less) of the pot; the idea is to approximate a charge "enclosed" by a conductor. Although the concept of charge capacitance need not be invoked to explain the demonstration, it is, of course, important that the two pots be identical in this respect. The capacitance of our pot was measured to be $42 \mathrm{pF}$ when sitting on a $25-\mathrm{cm}$ tall glass beaker above the ground plane. The voltage the pot will rise to will depend on its capacitance, among other things. Too large a voltage will cause the air to break down in the strong electric field and produce undesirable discharges. One way to prevent that 
Table II. Capacitances for several combinations of materials and thicknesses.

\begin{tabular}{lc}
\hline \hline Capacitance $(\mathrm{pF})$ & Material between pot and ground plane \\
\hline 42 & 25 -cm tall glass beaker \\
60 & $8 \times 8 \times 2$-in Pyrex baking dish \\
140 & $1 / 2$-in thick high-density polyethylene \\
220 & $1 / 2$-in thick fiberglass \\
380 & 2 -mm thick plastic tray \\
530 & $1 / 32$-in $(0.031$-in) thick Teflon sheet \\
600 & $1 / 16$-in thick phenolic (Garolite) sheet $^{\mathrm{a}}$ \\
910 & 0.010 -in thick Teflon sheet \\
\hline \hline
\end{tabular}

${ }^{\mathrm{a}}$ Reference 7.

${ }^{\mathrm{b}}$ Reference 8 .

from happening is to increase the capacitance, as can be seen from $V=Q / C$. This is accomplished by decreasing the distance between the pot and the ground plane as well as choosing an insulating support with a higher dielectric constant. To save the reader some experimentation time, Table II lists capacitances for several combinations of materials and thicknesses. Of course, an infinite number of combinations are possible, but a voltage reduction factor of 20 is probably about the best one can achieve with relatively common materials. That is to say, the capacitance of the pot sitting on a tall insulator can be increased by a factor of 20 .

Another way of reducing the voltage is simply to reduce the magnitude of the charge separation generated in the separation of the items of clothing. One can (1) lessen the contact area by judiciously arranging the clothing, (2) use smaller items of clothing or swatches of cloth, or (3) choose a clothing material combination that results in less charge separation.

\section{Clothing items and their handling}

A fleece and wool sweater make for a reliable combination that works well, readily producing a couple of $\mu \mathrm{C}$ of charge and therefore a voltage of $2 \mathrm{kV}$ for $C \approx 1000 \mathrm{pF}$. However, other combinations have worked well too: (a) fleece and cotton T-shirt, (b) fleece and silk shirt, and (c) cotton and silk. Their polarities are as expected from their order in the triboelectric series given in Table I.

Neatly fold the items of clothing to approximately the size of the bottom of the pot. Lay the sweater on the bottom and the fleece on top of the sweater. Press them together. Discharge both pots. Touch your own shirt sleeve and hand to the ground plane to remove stray charges before reaching back into the pot to retrieve the fleece. Do not touch the pot when you pull out the fleece. Immediately place the fleece into the other pot without touching that pot. Practice this well beforehand. If you hear crackling and discharges, you may very well be losing charge to somewhere not intended. In that case, lessen the amount of charge generated by reducing the intimate contact between the pieces of clothing, or use smaller pieces of the materials, or try any combination of the three suggestions in Sec. IV C above. If you are not getting enough charge separation, increase the contact area between the pieces of clothing. Note that what works brilliantly one day may not on another. Practice beforehand; you may very likely have to modify your technique depending on the humidity in the room.

\section{E. Checking the polarity of the charge}

The general procedure was described in Sec. III A. Since there will be a large charge on the pot, it will take a considerable test charge to change the deflection on the electroscope. To that end, use a generous piece of PVC pipe; 1 to 2 inches in diameter and 2 to 3 feet long. Before the demonstration, clean the pipe well with alcohol to remove oils and other surface contaminants. In the demonstration, rub a good length of the pipe with the cotton shirt to maximize the amount of charge on it. It is prudent to have washed the cotton shirt beforehand; don't use fabric softeners in the water or "no-cling" additives in the dryer. When inserting the PVC pipe into the pot, lower it down the middle as far as you can without touching the clothing.

\section{FINAL COMMENTS}

Although the demonstration is more finicky than the original version, it is well worth the extra effort. If so desired, the demonstration may also be performed with high-impedance digital electrometers. As was the case with the original version, a larger capacitance between the cooking pot and the ground plane will be required to keep the voltages well below $200 \mathrm{~V}$.

${ }^{1}$ W. Rueckner, D. Goodale, D. Rosenberg, and D. Tavilla, "Demonstration of charge conservation," Am. J. Phys. 63, 90-91 (1995).

${ }^{2}$ On the other hand, the list is not meant to be quantitative in the following sense. The actual separation of two materials on the list does not imply that their electrical interaction will be the same as two other materials on the list with the same degree of separation. For example, rubbing PVC with polyester (fleece) produces very little charge, so they are much closer in electrostatic characteristics than the order in the list suggests. PVC and Styrofoam are separated by seven other materials and so are nylon and acrylic; but one should not assume that the triboelectric effect is the same for these two pairs. A better list would group together materials with similar affinities to gain or lose electrons, and then rank those groups on a scale. Note also that some fabrics are "treated" in the manufacturing process and this can radically change their electrostatic characteristics. For example, a $100 \%$ nylon windbreaker jacket produced no charge when separated from a polyester fleece, yet these two fabrics are far apart on the list. Most likely the nylon had been treated so as to be water repellent. 100\% nylon panty hose often has Spandex added; again, this alters the electrostatic characteristics of nylon and little or no triboelectric effects were observed when coupled to polyester.

${ }^{3}$ Aluminum roof flashing (available in hardware stores) is an inexpensive solution.

${ }^{4}$ The two electroscopes shown in Fig. 1 are PASCO model SF-9069. $1 \mathrm{kV}$ (from a power supply) produces approximately a $30^{\circ}$ deflection; $2.5 \mathrm{kV}$ gives a $65^{\circ}$ deflection. The maximum voltage these electroscopes can handle is about $3 \mathrm{kV}$; they start to discharge along the surface of their insulation above that voltage.

${ }^{5}$ There are many on-line restaurant suppliers and you should "shop around." Our pots (Johnson-Rose Corp Black Label 6524) were purchased from insidekitchen.com for $\$ 38$ each.

${ }^{6}$ C. D. Hendricks, "Charging Macroscopic Particles," in Electrostatics and its Applications, edited by A. D. Moore (Wiley, New York, 1973), Chap. 4, p. 67.

${ }^{7}$ McMaster-Carr part number 8525K571.

${ }^{8}$ McMaster-Carr part number 8569K63 (also available down to 0.002-in thick). 